\title{
Comparison of Chemical Composition, Antifungal and Antibacterial Activities of Two Populations of Salvia macilenta Boiss. Essential Oil
}

\author{
Foroogh Mirzania $^{\oplus 1}$, Yaghoub Sarrafi ${ }^{\oplus * 1}$ and Mahdi Moridi Farimani ${ }^{\oplus * 2}$ \\ ${ }^{1}$ Department of Organic Chemistry, Faculty of Chemistry, University of Mazandaran, Babolsar, 47416- \\ 95447, Iran \\ ${ }^{2}$ Department of Phytochemistry, Medicinal Plants and Drugs Research Institute, Shahid Beheshti University, \\ G. C., Evin, Tehran, Iran
}

(Received October 23, 2017; Revised November 27, 2017; Accepted November 29, 2017)

\begin{abstract}
Salvia macilenta Boiss. is a fragrant subshrub which grows wild in some regions of Iran. In this work, we contrasted essential oil contents and components of two wild populations under two different ecological situations (Kerman and Baluchistan Provinces, Center and South East of Iran, respectively). For the first time the antibacterial and the antimycotic properties of these essential oils were also evaluated against seven bacterial and fungal strains. The essential oils were isolated by hydrodistillation method and the chemical compositions of the samples were examined by GC and GC-MS. Kerman (K) specimen was found to be rich in $\alpha$-pinene (29.0\%), $p$-cymene $(10.7 \%)$, veridiflorol (9.1\%), $\alpha$-eudesmol (8.7\%), bornyl acetate $(7.3 \%)$ with lesser concentrations of borneol (4.9\%). Principal components were identified as $\alpha$-eudesmol (35.6\%), $\alpha$-pinene (7.7\%), bornyl acetate $(7.6 \%)$, $(E)$-nerolidol $(6.5 \%)$ and veridiflorol (5.9\%) from Baluchistan (B) sample. Oxygenated sesquiterpenes were found to be the principal class of components in the oil of Baluchistan sample (53.0\%) whereas monoterpene hydrocarbons were the main class in Kerman specimen $(46.6 \%)$. The results demonstrated that the variety in the volatile compounds could be considered as chemotaxonomic importance and it may be ascribed to their different ecological and geographical source.
\end{abstract}

Keywords: Salvia macilenta Boiss.; essential oil; antibacterial activity; antifungal properties; GC/MS. C 2018 ACG Publications. All rights reserved.

\section{Plant Source}

Salvia macilenta is a fragrant subshrub which grows wild in Iran (Hormozgan, Baluchistan, Kerman and Yazd provinces). The aerial segments of $S$. macilenta of different origins were collected at the full flowering stage in April 2015 from Khash area, Zahedan, Baluchistan Province, Iran, and from Orzouyeh, Jiroft, Kerman Province, Iran. Voucher specimens have been deposited in the Medicinal Plants and Drugs Research Institute Herbarium (MPH-56 and MPH-2442 for Baluchistan and Kerman samples respectively), Shahid Beheshti University, Tehran, Iran.

\footnotetext{
* Corresponding authors: E-Mail: ysarrafi@umz.ac.ir (Y. Sarrafi), Phone: +98-1135302350 \&

E-Mail: m_moridi@sbu.ac.ir (M. M. Farimani), Phone: +98-2129904043.
} 


\section{Previous Studies}

The genus Salvia is one of the greatest and substantial fragrants of the Labiateae family. There are many reports on the chemical composition of the essential oils extracted from the plants belonging to the genus Salvia. In many Salvia species, $\alpha$-pinene, $\beta$-pinene, 1,8-cineole, borneol and camphene were observed as major components [1,2].

Salvia macilenta, an endemic species from Iran, a member of this great genus is a fragrant subshrub which grows wild in Iran. Antioxidant properties, neuroprotective effect, antiglycation activity, total phenolic and flavonoid components of this herb have been reported previously [3-5]. The results demonstrated that $S$. macilenta has high values of neuroprotective effects in addition to high antioxidant activities that imply the possibility of this plant as candidates for treating neurodegenerative diseases like Alzheimer's disease. Composition of the essential oil of S. macilenta growing wild in Hormozgan: Hajiabad, Golzar protected area, were investigated previously. In this investigation 31 components were characterized and the major components of oil were determined as $\alpha$-pinene $(60.0 \%), \gamma$-elemene $(6.1 \%)$, thymol (5.2\%), elemol (4.7\%), $\beta$-caryophyllene (4.1\%) and bornyl acetate (2.2\%) [3].

The dissimilarity in essential oil profile within the species offers encouragement for the prospects of breeding homogeneous plant material of S. macilenta with favorable commercial characteristics for particular uses. To verify this presumption, furthers studies under controlled conditions should be conducted in order to select interesting S. macilenta genotypes. In this study, we contrasted essential oil contents and components in two wild populations under two different ecological situations (Kerman and Baluchistan Provinces, Center and South East of Iran respectively). For the first time the antibacterial and the antimycotic properties of these essential oils were also evaluated against seven bacterial and fungal strains extracted from different origins. This selection is surely linked to its future success as industrial crop. This work should be made jointly with that aiming at the selection of suitable plants with high percentage of the desired compounds.

\section{Present Study}

The identified essential oils ingredients with their percents' are listed in order of their elution from a DB-5 column in Table 1 [6]. Our results demonstrated that "Baluchistan" population of $S$. macilenta contains more essential oils than "Kerman" population (densities of oils were $0.93 \mathrm{~g} / \mathrm{mL}$ and $0.92 \mathrm{~g} / \mathrm{mL}$ respectively). A comparison of the essential oil components in the two S. macilenta populations proved that there is discrepancy between these two populations as far as essential oils content and constituents are concerned. Main ingredients like $\alpha$-eudesmol, $\alpha$-pinene, $p$-cymene and bornyl acetate previously reported in this genus. For example, $\alpha$-pinene constituted the most abundant compound in the essential oils of S. rosifolia [7] (19.7\%), S. divaricata [8] (10.2\%) and S. recognita [9] (7. 6\%). Also, $\alpha$ eudesmol was one of the main compounds identified in S. microphylla [10] (14.1\%) and S. Africana [11] $(10.7 \%)$. Other main components like $p$-cymene was extracted and identified in S. verticillata [12] $(23.0 \%)$ and S. spinosa [13] (7.9\%). To our knowledge, no registered reports on variety of chemical compounds and oil yield of the essential oil of diverse populations of Salvia macilenta in the alpine areas in Southeastern and Centeral Iran (Baluchistan and Kerman province) are available. Presence of relatively large amounts of $(E)$-nerolidol and veridiflorol as oxygenated sesquiterpenes as well as $p$-cymene as monoterpene hydrocarbon in the essential oil of the aerial parts $S$. macilenta is reported for the first time in the present investigation.

In a study conducted by Sonboli and colleagues on the essential oil of this plant it was observed that concentrations of some ingredients were different than our research [3]. Because the essential oil components and their biological properties were found to be influenced by ecological factors. However, genetic agents also influence terpene biosynthesis pathways and consequently the principal characteristic ingredients and their percentages. These data permit an inventory, broadening of the variability of essential oil profiles of S. macilenta populations in Iran. Generally, it is proposed that this discrepancy in the major components of the essential oils of these plants may be attributed to differences in enviromental factors (climatic conditions, seasonal and geographic conditions, edaphic, elevation and topography, handling method, harvest period) and genetic (species, subspecies, ecotype, 
Table 1. Chemical composition of the oils of two populations of Salvia macilenta Boiss.

\begin{tabular}{|c|c|c|c|c|c|c|c|c|c|c|c|c|c|c|c|c|c|c|c|}
\hline Compounds & $\mathbf{R I}^{\mathrm{a}}$ & $\mathbf{R I}^{\mathbf{b}}$ & $\% \mathbf{B}$ & $\% \mathrm{~K}$ & Compounds & $\mathbf{R I}^{\mathrm{a}}$ & $\mathbf{R I}^{\mathbf{b}}$ & $\% \mathbf{B}$ & $\% \mathrm{~K}$ & Compounds & $\mathbf{R I}^{\mathbf{a}}$ & $\mathbf{R I}^{\mathbf{b}}$ & $\% B$ & $\% \mathrm{~K}$ & Compounds & $\mathbf{R I}^{\mathbf{a}}$ & $\mathbf{R I}^{\mathbf{b}}$ & $\% \mathrm{~B}$ & $\% \mathrm{~K}$ \\
\hline (3Z)-hexenal & 797 & 797 & 0.1 & 0.4 & (2E)-octenol acetate & 1211 & 1208 & 0.1 & $\mathrm{t}$ & $\gamma$-muurolene & 1473 & 1479 & 1.7 & 1.3 & $\alpha$-bisabolol acetate & 1799 & 1798 & 0.1 & $\mathrm{t}$ \\
\hline tricyclene & 925 & 921 & $\mathrm{t}^{\mathrm{c}}$ & 0.1 & trans-carveol & 1220 & 1215 & $\mathrm{t}$ & 0.1 & germacrene D & 1480 & $1479^{d}$ & $\mathrm{t}$ & 0.1 & phenyl ethyl octanoate & 1841 & 1846 & 0.4 & 0.1 \\
\hline$\alpha$-pinene & 936 & $939^{\mathrm{e}}$ & 7.7 & 29.0 & nerol & 1225 & 1227 & 0.02 & 0.1 & $\beta$-selinene & 1491 & 1489 & 1.1 & 0.7 & laurenene & 1882 & 1879 & 0.2 & $\mathrm{t}$ \\
\hline camphene & 951 & $952^{\mathrm{e}}$ & 1.0 & 3.9 & $\begin{array}{l}\text { tetrahydro-linalool } \\
\text { acetate }\end{array}$ & 1229 & 1231 & 0.03 & $\mathrm{t}$ & bicyclegermacrene & 1499 & 1500 & $\mathrm{t}$ & 1.1 & epi-laurenene & 1908 & 1901 & 0.2 & t \\
\hline thuja-2,4(10)-diene & 956 & 953 & 0.04 & 0.1 & tymol, methyl ether & 1236 & 1232 & 0.1 & $\mathrm{t}$ & $\alpha$-selinene & 1503 & 1498 & 1.0 & $\mathrm{t}$ & $(5 E, 9 E)$-farnesyl acetone & $\epsilon 1921$ & 1913 & 0.1 & $\mathrm{t}$ \\
\hline sabinene & 968 & 969 & 0.01 & $\mathrm{t}$ & pulegone & 1237 & 1233 & 0.3 & 1.0 & $\alpha$-muurolene & 1507 & 1500 & 0.5 & 0.4 & phytol & 1945 & 1942 & 0.2 & $\mathrm{t}$ \\
\hline$\beta$-pinene & 980 & $983^{\mathrm{d}}$ & 0.4 & 0.9 & $\begin{array}{l}\text { trans-2-hydroxy- } \\
\text { pinocamphone }\end{array}$ & 1243 & 1247 & 0.1 & $\mathrm{t}$ & $\beta$-bisabolene & 1510 & $1505^{\mathrm{f}}$ & 0.1 & $\mathrm{t}$ & cuparenic acid & 1929 & 1932 & 0.04 & 0.2 \\
\hline myrcene & 992 & $992^{\mathrm{e}}$ & 0.1 & 0.5 & cis-carvone oxide & 1251 & 1259 & 0.03 & $\mathrm{t}$ & $\gamma$-cadinene & 1517 & 1513 & 0.6 & 0.6 & nootkatin & 1962 & 1959 & 0.3 & $\mathrm{t}$ \\
\hline ethyl-(3E)-hexenoat & $e 1001$ & 1003 & 0.02 & $\mathrm{t}$ & geranial & 1259 & 1264 & 0.1 & $\mathrm{t}$ & eugenol acetate & 1528 & 1521 & $\mathrm{t}$ & 0.1 & $\begin{array}{l}\text { (Z)-methyl-isoprenyl } \\
\text { cinnamate }\end{array}$ & 1975 & 1970 & 0.1 & 0.1 \\
\hline$\delta$-3-carene & 1006 & $1008^{\mathrm{e}}$ & $\mathrm{t}$ & 0.1 & trans-anethol & 1278 & 1283 & 0.01 & $\mathrm{t}$ & $\delta$-cadinene & 1531 & $1523^{g}$ & 2.1 & 2.3 & $(Z, E)$-geranyl linalool & 1990 & $1998^{\mathrm{f}}$ & 0.1 & 0.1 \\
\hline limonene & 1020 & 1024 & 0.04 & $\mathrm{t}$ & bornyl acetate & 1287 & 1287 & 7.6 & 7.3 & $\alpha$-cadinene & 1536 & 1534 & 0.6 & 0.9 & manool oxide & 1995 & $1987^{\mathrm{f}}$ & 0.2 & $\mathrm{t}$ \\
\hline$\alpha$-terpinene & 1015 & $1018^{\mathrm{d}}$ & 0.01 & 0.3 & thymol & 1294 & 1289 & 0.2 & 0.3 & $\alpha$-calacorene & 1539 & 1544 & 0.6 & $\mathrm{t}$ & 13-epi-manool oxide & 2004 & 2009 & 0.1 & $\mathrm{t}$ \\
\hline$p$-cymene & 1020 & 1026 & 0.03 & 10.7 & carvacrol & 1297 & 1298 & 0.2 & 0.3 & elemol & 1552 & 1548 & $\mathrm{t}$ & 0.1 & abieta- 8,12 - diene & 2018 & 2022 & 0.04 & $t$ \\
\hline ortho-cymene & 1023 & 1022 & 2.4 & $\mathrm{t}$ & terpinen-4-ol acetate & 1303 & 1299 & 0.1 & 0.2 & germacrene B & 1559 & 1562 & 1.2 & $\mathrm{t}$ & $(E, E)$-geranyl linalool & 2021 & 2026 & 0.4 & 0.1 \\
\hline sylvestrene & 1027 & 1025 & 1.5 & $\mathrm{t}$ & iso-verbanol acetate & 1310 & 1308 & 0.2 & 0.3 & (E)-nerolidol & 1565 & 1561 & 6.5 & $\mathrm{t}$ & 4-hydroxy- stilbene & 2038 & 2042 & 0.4 & $\mathrm{t}$ \\
\hline (Z)- $\beta$-ocimene & 1033 & 1032 & $\mathrm{t}$ & 0.1 & 4-hydroxy-cryptone & 1319 & 1314 & 0.1 & 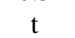 & aryophyllene oxide & 1587 & 1582 & 0.2 & 0.1 & kaurene & 2045 & 2042 & 0.04 & 0.1 \\
\hline$(E)$ - $\beta$-ocimene & 1048 & 1044 & $\mathrm{t}$ & 0.2 & myrtenyl acetate & 1322 & 1324 & 0.1 & $\mathrm{t}$ & cis- $\beta$-elemenone & 1595 & 1589 & $\mathrm{t}$ & 0.1 & manool & 2051 & 2056 & 0.1 & $\mathrm{t}$ \\
\hline 17 & 1052 & 1054 & 0.1 & 0.5 & $\delta$-elemene & 1329 & 1335 & 0.03 & $\mathrm{t}$ & globulol & 1598 & 1590 & 0.4 & 0.1 & sclarcolide & 2059 & 2065 & 0.4 & 0.2 \\
\hline terpinolene & 1079 & 1086 & $\mathrm{t}$ & 0.3 & terpenylacetate & 1354 & $1349^{\mathrm{g}}$ & 0.0 & $\mathrm{t}$ & guaiol & 1603 & 1600 & 0.3 & $\mathrm{t}$ & methyl linoleate & 2098 & 2095 & 0.1 & $\mathrm{t}$ \\
\hline$p$-cymenene & 1083 & 1089 & 0.1 & $\mathrm{t}$ & eugenol & 1365 & 1356 & 0.04 & $\mathrm{t}$ & geranyl isovalerate & 1608 & 1606 & 5.9 & 9.1 & laurenan-2-one & 2119 & 2115 & 0.1 & $\mathrm{t}$ \\
\hline linalool & 1099 & $1097^{\mathrm{g}}$ & 0.4 & 0.9 & carvacrol acetate & 1366 & 1370 & 0.1 & 0.3 & trans- $\beta$-elemenone & 1609 & 1601 & $\mathrm{t}$ & 0.1 & 7- isoprenyl oxycoumariı & 12122 & 2115 & 0.04 & $\mathrm{t}$ \\
\hline 6-camphenol & 1115 & 1111 & $\mathrm{t}$ & 0.3 & $\alpha$-ylangene & 1375 & 1373 & 0.3 & $t$ & 5-epi-7-epi- $\alpha$-eudesmol & 1612 & 1607 & 0.4 & $\mathrm{t}$ & methyl octadecanoate & 2128 & 2124 & 0.1 & $\mathrm{t}$ \\
\hline endo-f & 1119 & 1114 & 0.1 & $\mathrm{t}$ & $\alpha$-copaene & 1381 & 1374 & 1.4 & 1.4 & geranyl isovalerate & 1614 & 1606 & $\mathrm{t}$ & 0.1 & grandiflorene & 2171 & 2174 & 0.1 & $\mathrm{t}$ \\
\hline myrcenol & 1121 & 1119 & $\mathrm{t}$ & 0.2 & geranyl acetate & 1384 & 1379 & $\mathrm{t}$ & 0.1 & 10-epi- $\gamma$-eudesmol & 1619 & 1622 & 1.7 & 0.4 & phenethyl cinnamate & 2178 & 2179 & 0.4 & 0.1 \\
\hline 3-octanol acetate & 1120 & 1120 & 0.1 & $\mathrm{t}$ & $\beta$-bourbonene & 1386 & 1387 & 0.2 & $\mathrm{t}$ & $\gamma$-eudesmol & 1633 & 1630 & 1.5 & $\mathrm{t}$ & ethyl octadecanoate & 2199 & 2196 & 0.04 & $\mathrm{t}$ \\
\hline$\alpha$-capholenal & 1123 & 1122 & 0.2 & 0.3 & $\beta$-elemene & 1395 & 1389 & 0.1 & $\mathrm{t}$ & epi- $\alpha$-muuroiol & 1642 & 1640 & $\mathrm{t}$ & 0.5 & incensole oxide & 2282 & 2279 & 0.1 & $\mathrm{t}$ \\
\hline dihydro-linalool & 1133 & 1131 & $\mathrm{t}$ & 0.34 & sesquithujene & 1411 & 1405 & 0.6 & $\mathrm{t}$ & hinesol & 1645 & 1640 & 1.0 & $\mathrm{t}$ & trans-totarol & 2319 & 2314 & 0.2 & $\mathrm{t}$ \\
\hline trans-pi & 1138 & 1135 & 0.1 & $\mathrm{t}$ & (Z)-caryophyllene & 1413 & 1408 & 0.1 & $\mathrm{t}$ & $\beta$-eudesmol & 1653 & 164 & $\mathrm{t}$ & 0.2 & methyl dehydroabietate & 2338 & 2341 & 0.1 & $\mathrm{t}$ \\
\hline camphor & 1143 & 1141 & 0.3 & $\mathrm{t}$ & cis-nerone & 1420 & 1412 & $\mathrm{t}$ & 0.3 & vulgarone B & 1656 & 1649 & $\mathrm{t}$ & 0.1 & abietol & 2397 & 2401 & 0.1 & $\mathrm{t}$ \\
\hline isopulegol & 1147 & 1145 & 0.1 & 0.3 & $(E)$-caryophyllene & 1423 & 1417 & 1.1 & 0.8 & $\alpha$-eudesmol & 1658 & 1652 & 35.6 & 8.7 & totarolone & 2544 & 2542 & 0.1 & $\mathrm{t}$ \\
\hline$(E)$-2-nonenal & 1152 & 1155 & $\mathrm{t}$ & 0.5 & $\beta$-humulene & 1439 & 1436 & 0.1 & 0.1 & epi- $\beta$-bisabolol & 1671 & 1670 & 0.1 & $\mathrm{t}$ & \multicolumn{3}{|c|}{ Monoterpene Hydrocarbons } & 13.4 & 46.6 \\
\hline pinocarvone & 1157 & 1160 & 0.1 & $\mathrm{t}$ & (Z)- $\beta$-farnesene & 1445 & 1440 & 0.04 & $\mathrm{t}$ & cadalene & 1679 & 1675 & 0.6 & $\mathrm{t}$ & \multicolumn{3}{|c|}{ Oxygenated Monoterpenes } & 12.7 & 20.1 \\
\hline borneol & 1168 & 1165 & 1.2 & 4.9 & selina-3,7(11)-diene & 1451 & 1445 & $\mathrm{t}$ & 1.2 & elemol acetate & 1684 & 1680 & 0.1 & 0.3 & \multicolumn{3}{|c|}{ Sesquiterpene Hydrocarbons } & 15.0 & 9.9 \\
\hline umbellulone & 1169 & 1167 & $\mathrm{t}$ & 0.1 & geranyl acetone & 1456 & 1453 & 0.4 & $\mathrm{t}$ & germacrone & 1689 & 1693 & 0.1 & 0.1 & \multicolumn{3}{|c|}{ Oxygenated Sesquiterpenes } & 53.0 & 21.8 \\
\hline terpinen-4-ol & 1180 & 1174 & 0.3 & 1.1 & trans-prenyl limonene & $\epsilon 1464$ & 1457 & $\mathrm{t}$ & 0.1 & caryophyllene acetate & 1696 & 1701 & 0.1 & 0.1 & \multirow{2}{*}{\multicolumn{3}{|c|}{ Others }} & 4.1 & 0.8 \\
\hline$\alpha$-terpineol & 1182 & 1186 & 0.2 & 0.9 & sesquisabinene & 1466 & 1457 & $\mathrm{t}$ & 0.1 & $(2 E, 6 Z)$-farnesol & 1711 & 1714 & 0.1 & $\mathrm{t}$ & & & & & \\
\hline verbenone & 1199 & $1204^{\mathrm{f}}$ & 0.03 & 0.03 & allo-aromadendrene & 1467 & 1458 & $\mathrm{t}$ & 0.1 & $(2 E, 6 E)$-farnesol & 1739 & 1742 & 0.1 & $\mathrm{t}$ & \multirow{2}{*}{\multicolumn{3}{|c|}{ Total }} & 99.1 & 99.1 \\
\hline n-decanal & 1205 & 1201 & 0.18 & $\mathrm{t}$ & cabreuva oxide B & 1467 & 1462 & 0.28 & $\mathrm{t}$ & (Z)- $\alpha$-santalol acetate & 1770 & 1777 & 0.07 & 0.09 & & & & & \\
\hline
\end{tabular}

$\mathrm{a}=$ Retention Index (RI) calculated using $\mathrm{n}$-alkane series from $\mathrm{C}_{6}$ to $\mathrm{C}_{24}$ confirmed by comparison on DB-5MS; $\mathrm{b}=$ Retention Index (RI) from literature data [6]; $\mathrm{c}=$ relative percentage less than $0.01 \%$.

$\mathrm{B}=$ Baluchistan sample K=Kerman sample; $\mathrm{d}=[24] ; \mathrm{e}=[25] ; \mathrm{f}=[26] ; \mathrm{g}=[27]$ 
cultivar, chemotype, etc.), and their intraction effects are very effective on the type and percentage of components of essential oils. Many data published in the literature display that the essential oil content and the oil yield can be affected by genetic, climatic, and soil content, as well as by method of propagation, organ development and the date of accumulation of the herb material [14,15]. Also, several reports have demonstrated on the variation in Salvia essential oil composition induced by environmental, physiological and morphological factors that all of them state that, the observed interpopulation variation in the essential oil composition of sage might be the result of various complex factors, both endogenous and exogenous, such as geographical and climatic conditions [16, 17].

In this study the relevance between the geographical distribution and the essential oil composition was shown and separated these populations from each other. Further investigation of the composition of the essential oils from more populations of the Iran is necessary for the identification of possible chemotypes, while molecular analysis is needed to show the significance of terpenes as taxonomical markers in S. macilenta plant.

In vitro antimicrobial properties of essential oils was determined against some microorganisms. This research proved that the S. macilenta essential oil displayed antimicrobial activity on some Gram negative and Gram positive bacteria. The examined microorganisms are pathogens or compromiser for human, plants and animal, and they cause pollution and deterioration in food, air and water. The powerful antimicrobial property of the essential oil versus some sensitive microorganisms can be ascribed to the attendance of high concentration of monoterpenes. In the present study, monoterpenes, represented essentially by $\alpha$-pinene (monocyclic hydrocarbon); $\rho$ cymene (monocyclic aromatic); bornyl acetate (bicyclic oxygenated hydrocarbon) and borneol (bicyclic alcohol) were found to be the major compounds. Antimicrobial activities of $\alpha$-pinene, $\alpha$ eudesmol and bornyl acetate were presented only in a few publications $[18,19]$ but the biological properties of these compounds have been reported in a large number of papers. The MIC values for antimicrobial activity of $\alpha$-pinene against $C$. albicans, $C$. neoformans and $R$. oryzae were 3125,117 and $390 \mu \mathrm{g} / \mathrm{mL}$ respectively [19]. As well $p$-cymene is an important intermediate used in pharmaceutical industries and for the production of pesticides, fungicides and as flavoring compound [20]. Previous studies demonstrated that $p$-cymene was able to present analgesic and antiinflammatory activities in mice [20]. Also, in other research the antinociceptive and anti-inflammatory actions of the $p$-cymene were reported [21]. The anti-neurogenic inflammation action of $\alpha$-eudesmol that becomes useful for the treatment of the neurogenic inflammation in the trigemino-vascular system such as migraine was reported previously [22]. Also, in other report the analgesic and antiinflammatory effects of bornyl acetate illustrated [23]. It is difficult to ascribe the antimicrobial properties of an essential oil to one or a few active ingredients, but it may be concluded that much more $\alpha$-eudesmol, $\alpha$-pinene and bornyl acetate in the Baluchistan sample caused the more antimicrobial activity of this sample. So, antibacterial activities of $S$. macilenta essential oils demonstrated that this herb has potential for use in aromatherapy and pharmacy. This in vitro experimental investigation obviously revealed the efficient bactericidal act of $S$. macilenta essential oil and patronage the freely usage of this natural eco-friendly mixture as a preservative in food and water which are sensitive for producing mellow scent. The results represented here can be considered as the first information on the antimicrobial and antifungal activity of aerial portions essential oil of $S$. macilenta. Antibacterial activity of the essential oil of $S$. macilenta could be considered as a supplementary health elevating factor. Therefore, additional researches are indispensable to evaluate the specifications of each population which grows in various soil and climatic situations. As a conclusion, the main constituents of these essential oils of $S$. macilenta, include $\alpha$-pinene, $p$-cymene, veridiflorol, $\alpha$-eudesmol, bornyl acetate, borneol, $\alpha$-eudesmol and $(E)$-nerolidol. The data presented in this investigation showed a high variation of the essential oil composition among Iranian S. macilenta populations harvested from different bioclimatic zones. The essential oil components and their biological properties were found to be influenced by ecological factors. However, genetic agents also influence terpenes biosynthesis pathways and therefore the main components and their percentages. To verify this hypothesis, furthers investigations under controlled situations should be conducted in order to select interesting $S$. macilenta genotypes. This selection is surely linked to its future achievement as industrial crop. 


\section{Acknowledgements}

We warmly thank Dr. Seyed Mansour Mirtajadini, Biology Department of Shahid Bahonar University of Kerman, Kerman, Iran for plant material collection.

\section{Supporting Information}

Supporting Information accompanies this paper on http://www.acgpubs.org/RNP

\section{ORCID}

Foroogh Mirzania : $\underline{0000-0003-4072-4233}$

Yaghoub Sarrafi : 0000-0002-1351-9720

Mahdi Moridi Farimani: 0000-0001-9273-1019

\section{References}

[1] S. D. Hatipoglu, N. Zorlu, T. Dirmenci, A. C. Goren, T. Ozturk and G. Topcu (2016). Determination of volatile organic compounds in fourty five Salvia species by thermal desorption-GC-MS technique, Rec. Nat. Prod. 10, 659-700.

[2] N. Gursoy, B. Tepe and H. A. Akpulat (2012). Chemical composition and antioxidant activity of the essential oils of Salvia palaestina (Bentham) and S. ceratophylla (L.), Rec. Nat. Prod. 6, 278-287.

[3] A. Sonboli, A. R. Fakhari and F. Sefidkon (2005). Chemical composition of the essential oil of Salvia macilenta from Iran, Chem. Nat. Comp. 41, 168-170.

[4] S. K. Tusi and F. Khodagholi (2014). Salvia macilenta exhibits antiglycating activity and protects PC12 cells against $\mathrm{H}_{2} \mathrm{O}_{2}$-induced apoptosis, Cytotech., 66, 169-179.

[5] S. Asadi, A. Ahmadiani, M. A. Esmaeili, A. Sonboli, N. Ansari and F. Khodagholi (2010). In vitro antioxidant activities and an investigation of neuroprotection by six Salvia species from Iran: a comparative study, Food Chem. Toxicol., 48, 1341-1349.

[6] R. P. Adams (2007) Identification of essential oil components by gas chromatography/quadrupole mass spectroscopy. Allured, Carol Stream.

[7] B., Demirci, K. Hüsnü Can Başer, B. Yıldız and Z. Bahçecioğlu (2003). Composition of the essential oils of six endemic Salvia spp. from Turkey, Flav. Frag. J. 18, 116-121.

[8] T. Kilic, T. Dirmenci and A.C. Goren (2007). Chemotaxonomic evaluation of species of Turkish Salvia: Fatty acid composition of seed oils, II, Rec. Nat. Prod. 1, 17-23.

[9] B. Demirci, F. Demirci, A. Donmez, G. Franz, D. Paper and K. Husnu Can Baser (2005). Effects of Salvia essential oils on the chorioallantoic membrane (CAM) assay, Pharm. Biol. 43, 666-671.

[10] R. K. Lima, M. das Graças Cardoso, M. A. Andrade, P. L. Guimarães, L. R. Batista and D. L. Nelson, (2012). Bactericidal and antioxidant activity of essential oils from Myristica fragrans Houtt and Salvia microphylla HBK, J. American Oil Chem. Soc. 89, 523-528

[11] L. De Martino, G. Roscigno, E. Mancini, E. De Falco and V. De Feo (2010). Chemical composition and antigerminative activity of the essential oils from five Salvia species, Molecules, 15, 735-746.

[12] D. Pitarokili, O. Tzakou and A. Loukis (2006). Essential oil composition of Salvia verticillata, S. verbenaca, S. glutinosa and S. candidissima growing wild in Greece, Flav. Frag. J. 21, 670-673.

[13] M. S. Sourmaghi, G. Amin, N. Samadi, F. Hemmati and P. Sarkhail (2006). Chemical composition and antimicrobial activity of essential oil of Salvia spinosa L., Asian J. Plant Sci, 5, 654-656.

[14] S. N. Ebrahimi, J. Hadian, M. H. Mirjalili, A. Sonboli and M. Yousefzadi (2008). Essential oil composition and antibacterial activity of Thymus caramanicus at different phenological stages, Food Chem., 110, 927-931.

[15] M. Couladis, P. Baziou, P. V. Petrakis and C. Harvala (2001). Essential oil composition of Hypericum perfoliatum L. growing in different locations in Greece, Flav. Frag. J., 16, 204-206.

[16] B. Fattahi, V. Nazeri, S. Kalantari, M. Bonfill and M. Fattahi (2016). Essential oil variation in wildgrowing populations of Salvia reuterana Boiss. collected from Iran: Using GC-MS and multivariate analysis, Indust. Crops Prod., 81, 180-190.

[17] M. Skoula, J. E. Abbes and C. B. Johnson (2000). Genetic variation of volatiles and rosmarinic acid in populations of Salvia fruticosa mill growing in Crete, Biochem. System. Eco., 28, 551-561. 
[18] H. J. D. Dorman and S. G. Deans (2000). Antimicrobial agents from plants: Antibacterial activity of plant volatile oils, J. App. Microb., 88, 308-316.

[19] A. C. R. D. Silva, P. M. Lopes, M. M. B. D. Azevedo, D. C. M. Costa, C. S. Alviano and D. S. Alviano (2012). Biological activities of $\alpha$-pinene and $\beta$-pinene enantiomers, Molecules, 17, 6305-6316.

[20] J. D. S. S. Quintans, P. P. Menezes, M. R. V. Santos, L. R. Bonjardim, J. R. G. S. Almeida, D. P. Gelain and L. J. Quintans-Júnior (2013). Improvement of $p$-cymene antinociceptive and anti-inflammatory effects by inclusion in $\beta$-cyclodextrin, Phytomed. 20, 436-440.

[21] L. R., Bonjardim, E. S., Cunha, A. G. Guimarães, M. F. Santana, M. G. Oliveira, M. R. Serafini and L. J. Quintans-Júnior (2012). Evaluation of the anti-inflammatory and antinociceptive properties of $p$ cymene in mice, Z. Naturforsch. C, 67, 15-21.

[22] K. Asakura, T. Kanemasa, K. Minagawa, K. Kagawa, T. Yagami, M. Nakajima and M. Ninomiya (2000). $\alpha$-Eudesmol, a P/Q-type Ca 2+ channel blocker, inhibits neurogenic vasodilation and extravasation following electrical stimulation of trigeminal ganglion, Brain Res. 873, 94-101.

[23] X. Wu, X. F. Li, Xiao, Z. Zhang, Z. Xu and H. Wang (2004). Studies on the analgesic and antiinflammatory effect of bornyl acetate in volatile oil from Amomum villosum, J. Chin. Med. Mat., 27, 438-439.

[24] I. Rasooli, and S. A. Mirmostafa (2002). Antibacterial properties of Thymus pubescens and Thymus serpyllum essential oils, Fitoterap., 73, 244-250.

[25] A. Pichette, P. L. Larouche, M. Lebrun and J. Legault (2006). Composition and antibacterial activity of Abies balsamea essential oil, Phytother. Res., 20, 371-373.

[26] D. Stojković, M. Soković, J. Glamočlija, A. Džamić, A. Ćirić, M. Ristić and D. Grubišić (2011). Chemical composition and antimicrobial activity of Vitex agnuscastus L. fruits and leaves essential oils, Food Chem., 128, 1017-1022.

[27] N. U. Çolak, S. Yıldırım, A. Bozdeveci, N. Yayli, K. Çoşkunçelebi, S. Fandaklı and A. Yaşar (2017). Essential Oil Composition, Antimicrobial and Antioxidant Activities of Salvia staminea, Rec. Nat. Prod., 12, 86-94.

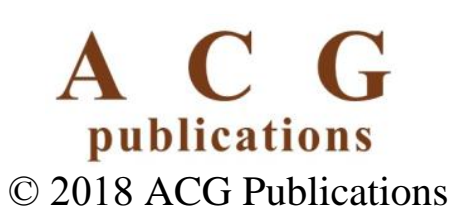

